\title{
O trabalho dos professores de Ciências e Biologia dos colégios estaduais de Tibagi-PR: precarização e naturalização
}

\author{
Elisângela Aparecida Ferreira de Lima*, Rodrigo Diego de Souza**
}

\section{Resumo}

O estudo sobre as condições de trabalho dos Professores é fundamental para pensar criticamente a Prática Pedagógica na Educação em Ciências e Biologia, nessa direção, o objetivo desta pesquisa consistiu em analisar as características e perspectivas dos docentes sobre o trabalho dos professores de Ciências e Biologia de Tibagi-PR nas especificidades e na singularidade desta cidade paranaense. Para tanto, fez-se um estudo teórico e de campo empírico com sete professores que atuam nos quatro Colégios Públicos Estaduais, localizados nas Zonas Urbana e Rural do município. Os dados foram analisados qualitativamente, em que se constatou: 1) a necessidade da democratização da Educação e do acesso à Educação; (2) a naturalização da precarização das condições objetivas do trabalho dos professores em questão; (3) a garantia de políticas de valorização e manutenção dos professores nas cidades interioranas e nas zonas rurais, pois a maioria dos professores estão próximos da aposentadoria e são poucos os novos professores atuantes nos colégios da região em estudo; (4) a culpabilização apenas dos alunos como desinteressados pelas aulas em detrimento de uma visão mais ampla de todas as condições estruturais que permeiam os processos educativos no Ensino de Ciências e Biologia. Neste artigo estão as análises iniciais desta pesquisa, considerando-se que o estudo terá continuidade.

Palavras-chave: Educação em Ciências. Ensino de Biologia. Professores de Biologia. Trabalho.

\footnotetext{
Licenciada em Ciências Biológicas, Universidade Estadual de Ponta Grossa (UEPG). Email: elisangelabiouepg@ gmail.com

** Professor Adjunto da Faculdade de Educação da Universidade de Brasília (FE/UnB). Doutor em Educação Científica e Tecnológica pela Universidade Federal de Santa Catarina (UFSC). Email: professor.rodrigosouza@ gmail.com
} 


\section{Introdução}

O trabalho é uma atividade que propicia ao homem mudar sua realidade; e, ao transformá-la, transforma a si mesmo, constituindo-se pelo trabalho (MARX, 2002). Nesse entendimento, faz-se necessário discutir, na Educação em Ciências, as condições de trabalho nas quais os professores de Ciências e Biologia inserem-se, constituem-se e produzem a sua vida. Atrelada a isso, a motivação é um dos fatores que tem grande influência no trabalho docente, muito abalada pela desvalorização e condições de trabalho muitas vezes precárias, assim como a falta de interesse dos alunos.

Desse modo, na docência, o bem-estar existe a partir da junção das características pessoais dos professores e alunos e das condições materiais existentes para que se estabeleçam relações harmônicas entre eles. Isso garante o bom desenvolvimento tanto na aprendizagem como em maior dedicação do professor e, por consequência, em bem-estar profissional; a partir disso, o professor se sente à vontade para continuar na docência. No entanto, muitas vezes esse bem-estar não ocorre, causando a desistência da profissão devido ao mal estar, à não realização profissional e à precarização do trabalho que se dá nas condições objetivas, materiais de trabalho, salário, remuneração, entre outras.

As condições já colocadas estão dadas a todos os docentes, e, na singularidade dos professores de Ciências e Biologia, os autores Delizoicov, Angotti e Pernambuco (2011, p. 31) apontam que a Educação em Ciências enfrenta dificuldades, começando pela formação dos professores. Dominar as teorias científicas não é o suficiente para a prática pedagógica, muito próxima do senso comum, em que ensinar está relacionado à mecanização e à transmissão dos conteúdos, o que passa a ser potencializado com as dificuldades estruturais do trabalho.

Nessa perspectiva, a primeira autora deste artigo ressalta, a partir de sua experiência formativa, que algo que contribui muito para as primeiras motivações do licenciando é o momento do Estágio Supervisionado Curricular Obrigatório, sendo muitas vezes o primeiro contato dele com a escola, o que pode ser satisfatório ou frustrante.

O estágio é a oportunidade de se conhecer e familiarizar-se com o público e o ambiente escolar como professor. Barros, Silva e Vasquez (2011) apontam que o estágio é o momento de aprender, de atribuir técnicas de como agir em sala de aula, 
de observar a relação professor-aluno, de cometer erros e aprender a lidar com eles, de enfrentar medos e superar obstáculos. No entanto, salientamos que compreendemos o estágio como a síntese entre a teoria e a prática e não uma aplicação das teorias na prática.

Considerando-se os aspectos supracitados, em especial a trajetória e as vivências da pesquisadora (primeira autora) deste artigo, na problemática central do estudo indaga-se as relações de trabalho dos professores de Ciências e Biologia e tem-se por objetivo analisar as características e perspectivas dos docentes sobre $o$ trabalho dos Professores de Ciências e Biologia de Tibagi-PR, nas especificidades e na singularidade desta cidade paranaense.

Para isso, inicialmente se apresentam os aspectos teóricos referentes ao que compreendemos como Trabalho e, então, as reflexões e discussões acerca do estudo empírico. Ressalta-se que tendo em vista a complexidade teórica que fundamenta este artigo, optou-se por apresentar aqui as análises iniciais dos dados da pesquisa.

\section{Reflexões acerca do trabalho dos professores}

O trabalho na vida profissional dos professores se configura como trabalho docente e tem dimensão pedagógica. O professor vai construindo sua trajetória profissional e educativa ao longo do caminho, incorporando atitudes e conceitos que farão parte de sua constituição enquanto docente, como Santos, Antunes e Bernardi (2008, p. 38) afirmam:

O educador, em qualquer instância ou representação de ensino formal, representa um ser humano ímpar em subjetividades, inter-relações e construções de saberes. Sempre em desenvolvimento, compõe em si valores, hábitos, concepções e ações educativas que o identificam como tal.

Entretanto, articulado ao trabalho docente e pedagógico está a perspectiva do trabalho como fundamento ontológico do ser social, ou seja, o trabalho como aquele que dá as condições para a produção e reprodução da vida dos professores. Essa concepção ontológica do trabalho está para além da concepção reducionista e, muitas vezes, polissêmica do trabalho docente alinhado apenas aos aspectos pedagógicos e da sala de aula (MARX, 1974; LUKÁCS, 1979; LUKÁCS, 2012; LUKÁCS, 2013).

Assim, neste estudo, dentre os conceitos referentes ao Trabalho, compartilha-se a perspectiva do trabalho como fundamento do ser social, a qual é apontada inicial 
e fundamentalmente em Marx (2002, p. 211), quando afirma ser o trabalho, nessa concepção,

[...] um processo de que participam homem e natureza, processo em que o ser humano, com sua própria ação, impulsiona, regula e controla o intercâmbio material com a natureza. Defronta-se com a natureza como uma de suas forças. Põe em movimento as forças naturais do seu corpo - braços, pernas, cabeça e mãos -, a fim de aproximar-se dos recursos da natureza, imprimindo lhes forma útil a vida humana. Atuando assim sobre a natureza externa e modificando-a, ao mesmo tempo modifica sua própria natureza.

Nessa direção, o trabalhador estabelece relação com o produto por ele gerado, entretanto, na sociedade capitalista na qual o trabalhador vende a sua força de trabalho, o produto do seu trabalho e a sua força de trabalho não pertencem a ele, mas, sim, a quem as comprou (ENGUITA, 1989, p. 169).

No caso dos professores, esta relação está explícita quando atuam nos colégios privados; no entanto, quando atuam em Escolas Públicas e o seu trabalho não gera um lucro a um comprador específico, ele vende a sua força de trabalho para o Estado. Este, na maioria das vezes, precariza o trabalho de inúmeras formas, desde às condições objetivas de trabalho até aos salários que proveem a sobrevivência e não a vida com um salário digno para os docentes.

Entendendo, a partir dos estudos da perspectiva marxista, que a compreensão do Estado na sociedade capitalista consiste na legitimação da propriedade privada, as relações de exploração entre o estado e os professores também ocorrem mesmo não existindo a expectativa do lucro como na iniciativa privada. Aspectos relacionados às discussões supracitadas também são apresentadas e aprofundadas em pesquisas como as desenvolvidas por Grochoska (2015), Moretti e Masson (2015), Masson (2016) e Souza (2019).

Relacionado a isso, Silva e Rosso (2008, p. 2041) apontam para aspectos pertinentes das inúmeras questões que atravessam a realidade dos professores quando afirmam:

Quando o assunto é a melhoria das condições de vida e trabalho dos professores, a atenção é dada para as suas condições do exercício da profissão que são determinadas por vários fatores como as condições em que se encontram as escolas e as condições de trabalho, a relação entre os professores e o controle burocrático imposto a eles interna e externamente. Isso tudo trás consequências aos docentes, afetando psicologicamente, gerando o estres, o desinteresse e uma queda na qualidade da prática da profissão e de vida. Além de ministrar as aulas os professores precisam de horas 
para prepará-las, elaborar novos métodos e atividades para melhor compreensão e aprendizado dos alunos, fazer a correção de inúmeras atividades/trabalhos e provas. Todo esse trabalho é destinado à hora atividade que não é suficiente, com o professor tendo assim que levar trabalho para casa, deixando de lado suas atividades de lazer para poder dar conta do trabalho que deveria ser feito em suas horas na escola para a qual cabe o seu desvalorizado salário.

De acordo com Cruz et al. (2010, p. 152), o professor adquire e constrói durante a sua formação e carreira um saber que é confrontado no seu trabalho com a responsabilidade de lidar com várias turmas, numa média de quarenta alunos por turma. Para isso, tenta atualizar seus conhecimentos por meio de novos métodos e tecnologias, o que lhe exige esforços extras e ultrapassa a carga horária para a qual é pago.

Além disso, ainda existem as chamadas atividades burocráticas que o professor precisa cumprir, como preencher os diários de classe com o registro de frequência dos alunos e das atividades avaliativas feitas. Estas, por fazerem parte da rotina do professor, muitas vezes passam a ser realizadas em casa.

Sendo assim, o trabalho dos professores não pode ser dividido entre outros professores como é feito em uma fábrica, por exemplo, em que cada atividade é responsabilidade de alguém em diferentes setores. Assim, tendo que ser iniciado e terminado pelo mesmo professor, pois:

No imaginário popular o fazer docente é visto mais como uma vocação, uma missão a ser desempenhada, do que propriamente uma profissão. Assim sendo, a remuneração do educador carrega consigo um atributo que se assemelha mais a uma "ajuda de custo" do que propriamente o pagamento pelas atividades desenvolvidas (BENEVIDES-PEREIRA, 2012, p. 156).

Associado ao que fora supracitado, Gasparini, Barreto e Assunção (2005, p. 191) apontam reflexões muito pertinentes também:

$\mathrm{Na}$ atualidade, o papel do professor extrapolou a mediação do processo de conhecimento do aluno, o que era comumente esperado. Ampliou-se a missão do profissional para além da sala de aula, a fim de garantir uma articulação entre a escola e a comunidade. O professor, além de ensinar, deve participar da gestão e do planejamento escolares, o que significa uma dedicação mais ampla, a qual se estende às famílias e à comunidade.

Partindo-se dessas reflexões acerca do trabalho dos professores, apresentam-se os aspectos referentes à pesquisa empírica. 


\section{O trabalho dos professores de ciências e biologia de Tibagi-PR: contextualizando geograficamente a pesquisa de campo empírico}

Tibagi é um município brasileiro localizado na região dos Campos Gerais no Estado do Paraná, localizado a $200 \mathrm{~km}$ da capital. A cidade foi fundada em $1872 \mathrm{e}$ possui uma área de extensão de $3.108,746 \mathrm{~km}^{2}$.

A economia do município se baseia na produção de grãos, na criação de animais como bovinos e suínos e num forte investimento no setor turístico. Segundo os dados do último IBGE, realizado em 2010, a população era de 19.332 habitantes, em que mais da metade se encontra na Zona Rural, nos distritos Caetano Mendes e Alto do Amparo e nas diversas comunidades como Barreiro, Pinheiro Seco, São Bento, Cachoeirão, Barra Mansa, Cerrado Grande, Iapará, Serra Gaias, Agudos, Porteira Grande, Campina Alta, Vila Rural Santa Rosa, Guartelá, Santo Amaro, Lavras, Conceição e Penha.

Para uma melhor visualização da localização geográfica do município de Tibagi, no Paraná, consta a seguir um mapa na Figura 1:

Figura 1: Localização do município de Tibagi no mapa do Estado do Paraná

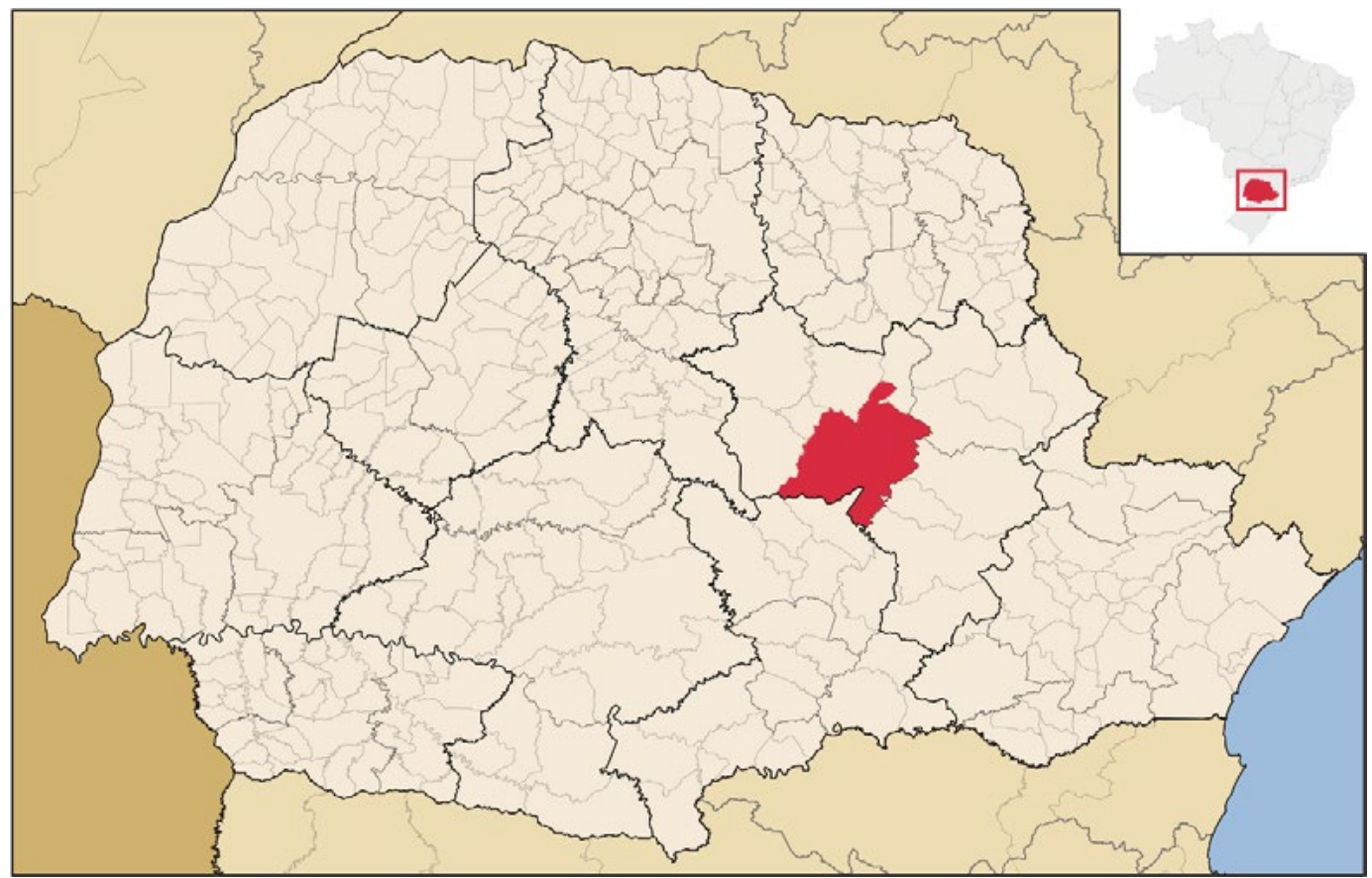

Fonte: https://upload.wikimedia.org/wikipedia/commons/thumb/a/aa/Parana_Municip_Tibagi.svg/300px-Parana_Municip_Tibagi. svg.png. Acesso em: 5 maio 2019. 
O município conta com quatro Colégios Públicos Estaduais, dois localizados na Zona Urbana (Colégio Leopoldina e Colégio Irênio) e dois na Zona Rural (Colégio Baldomero e Colégio João Francisco).

O Colégio Irênio, localizado no centro da cidade, possui uma área total de 5.940,50 m², sendo que 1.117,06 m² são de área construída, com 03 blocos com 08 salas de aula. Conta com 822 alunos, entre Ensino Fundamental, Ensino Médio, EJA e Ensino Profissionalizante. De acordo com os dados coletados no período de desenvolvimento da pesquisa empírica, havia 127 alunos matriculados em atividades complementares, como sala de apoio em Português, Matemática, Inglês e Espanhol Básico, e 44 Professores.

Também localizado no centro da cidade, o Colégio Leopoldina, na ocasião da coleta de dados, tinha 731 alunos matriculados no Ensino Fundamental e Médio, dos quais 36 em atividades complementares, e um número de 34 Professores. Possui um terreno com área total de 5.466,98 m² e 1.319,19 m² de área construída, com 06 blocos e 08 salas de aula.

Localizado no distrito de Alto Amparo na zona rural a $40 \mathrm{~km}$ da cidade de Tibagi e $55 \mathrm{~km}$ da cidade de Ponta Grossa, o Colégio Baldomero possui 4.415,17 $\mathrm{m}^{2}$ de área total e $615,45 \mathrm{~m}^{2}$ de área construída, com 03 blocos e 07 salas de aula. $\mathrm{O}$ Colégio conta com 461 alunos matriculados, entre Ensino Fundamental e Médio, e 25 Professores que, em sua maioria, são moradores da cidade de Ponta Grossa, de acordo com os dados coletados.

Embora a cidade de Tibagi seja mais próxima do Alto do Amparo, são os professores de Ponta Grossa que costumam ir lecionar no Colégio Baldomero, pois as estradas que ligam Tibagi até o Colégio são em grande parte estradas de terra e muitas vezes de difícil acesso. Dessa maneira, na cidade, não há transporte coletivo para a população nem transporte ofertado pelo município aos professores que moram em Tibagi, tendo que fazer uso de condução própria. Já a cidade de Ponta Grossa, até a localidade onde se encontra o colégio, possui rotas rodoviárias contando com ônibus metropolitanos e convencionais com variados horários. Isso facilita o deslocamento dos professores até lá, o que diminui a busca de professores do próprio município.

Também com localização na Zona Rural do município, no distrito de Caetano Mendes, a $32 \mathrm{~km}$ da cidade de Tibagi, o Colégio João Francisco, durante a coleta de dados, contava com 478 alunos matriculados, entre Ensino Fundamental e Médio, e 
26 Professores. Possui uma área total de $10.000 \mathrm{~m}^{2}$ e 1.097,11 m² de área construída, com 04 blocos e 11 salas de aula.

Na Figura 2, a seguir, é possível observar a distribuição dos Colégios Públicos Estaduais no território de Tibagi:

Figura 2: Localização dos colégios estaduais de Tibagi-PR no mapa do município - 2019

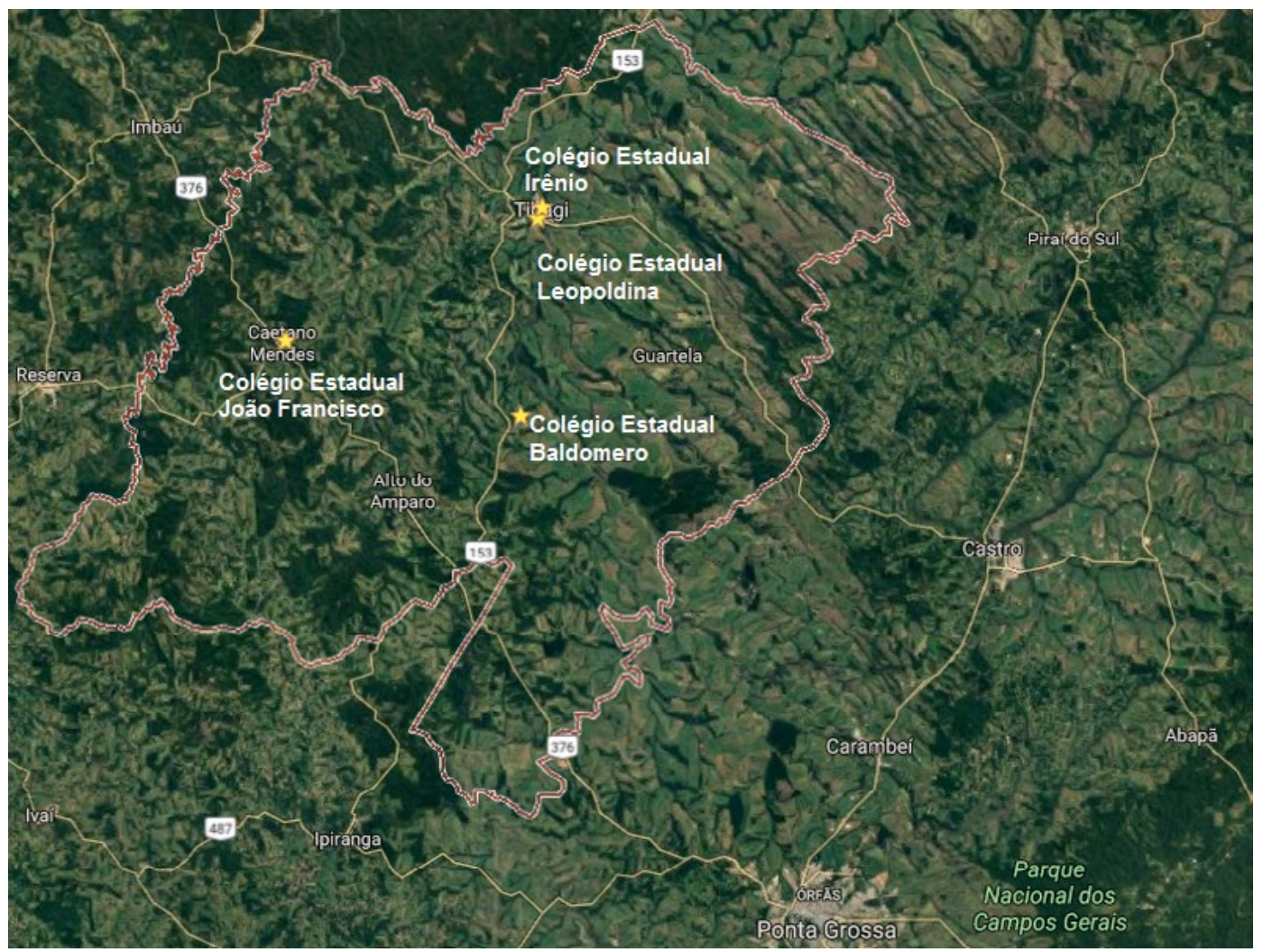

Fonte: mapa adaptado do Google Maps. Disponível em: https://www.google.com.br/maps/place/Tibagi+-+PR,+84300-000/@-24.6838106. Acesso em: 5 maio 2019.

\section{A caracterização do trabalho dos professores de ciências e biologia de Tibagi-PR}

O estudo de campo empírico desta pesquisa, caracterizado qualitativamente (FLICK, 2009), aconteceu com sete professores de Ciências e Biologia que atuam nos quatro colégios públicos de Tibagi-PR. A coleta de dados ocorreu entre os meses de julho e setembro do ano de 2017. Todos os participantes assinaram o termo 
de consentimento livre e esclarecido (em anexo), concordando em participar da pesquisa, conforme prescreve a Resolução no 466, de 12 de dezembro de 2012, do Conselho Nacional de Saúde. A Tabela 1 apresenta a caracterização dos sujeitos que participaram da pesquisa.

Tabela 1: Caracterização dos sujeitos da pesquisa: professores de Ciências e Biologia que atuam nas instituições escolares de Tibagi/PR- jul./set. $2017\left(^{*}\right)$

\begin{tabular}{l|c|c|c|c|c}
\hline \multicolumn{1}{c|}{ Sujeitos da Pesquisa } & \multirow{2}{*}{ Amostragem } & \multicolumn{2}{c|}{ Gênero } & \multicolumn{2}{c}{ Idade } \\
\cline { 3 - 6 } & & M & F & $31-45$ & $46-60$ \\
\hline $\begin{array}{l}\text { Professores de Ciências e Biologia que } \\
\text { atuam na Zona Urbana de Tibagi/PR }\end{array}$ & $42 \%(3)$ & & & & \\
$\begin{array}{l}\text { Professores de Ciências e Biologia que } \\
\text { atuam na Zona Rural de Tibagi/PR }\end{array}$ & $28 \%(2)$ & $28 \%(2)$ & $71 \%(5)$ & $56 \%(4)$ & $42 \%(3)$ \\
$\begin{array}{l}\text { Professores de Ciências e Biologia que atuam } \\
\text { na Zona Urbana e Rural de Tibagi/PR }\end{array}$ & $28 \%(2)$ & & & & \\
\hline $\begin{array}{l}\text { Total de Participantes } \\
\text { (*) Margem de erro em torno de 2\%. }\end{array}$ & & \multicolumn{3}{|c}{$100 \%(7)$} \\
Fonte: dados de pesquisa dos autores (2017).
\end{tabular}

Com a sistematização das informações referentes ao gênero e à idade dos professores, constata-se que dos sete sujeitos, $42 \%$ atuam apenas na zona urbana, $28 \%$ na zona rural e $28 \%$ na zona urbana e rural. Além disso, observa-se que $71 \%$ são sujeitos do sexo feminino, estando de certa forma alinhado a outras pesquisas que já sinalizam que a maioria das pessoas que optam pela escolha do trabalho docente são do sexo feminino.

Segundo Neves e Silva (2006, p. 67), a feminização do magistério, na divisão social e sexual do trabalho, apresenta dimensões históricas. Na saída do confinamento doméstico, a conquista das mulheres por postos de trabalho, nas condições históricas dadas, apenas se encontrava comumente em profissões de magistério e outros empregos relacionados com as atividades domésticas.

Também se observa que, dentre os sujeitos da pesquisa, $42 \%$ são professores que têm idade entre 46 e 60 anos, $0 \%$ entre 18 e 30 anos e $56 \%$ com idade entre 31 a 45 anos. Por Tibagi ser uma cidade interiorana e com distritos e localidade de difícil acesso, no que diz respeito aos Colégios da Zona Rural de Tibagi que são mais próximos de cidades vizinhas que do próprio município, ocasiona não ser algo tão 
atrativo para os jovens professores. Nessa direção, fazem-se necessárias políticas de valorização e manutenção dos professores nesses espaços de trabalho, pois a maioria dos professores estão em vias de se aposentarem e há poucos professores jovens atuando nos Colégios da região.

Esses elementos são salientados também por estudos produzidos pelo Ministério da Educação no Brasil, como aponta um dos Cadernos de Subsídios da Educação do Campo, elaborado pela extinta Secretaria de Educação Continuada, Alfabetização e Diversidade, quando diz:

[...] as condições de trabalho dos profissionais do magistério permanecem precárias. No caso específico da área rural, além da baixa qualificação e dos salários inferiores aos da zona urbana, eles enfrentam, entre outros problemas, sobrecarga de trabalho, alta rotatividade e dificuldade de acesso à escola, em função das condições das estradas e da falta de ajuda de custo para a locomoção (BRASIL, 2007, p. 33).

A partir disso, para a coleta de dados, com o intuito de caracterizar o trabalho dos professores em sua particularidade no munícipio de Tibagi-PR, os docentes responderam um questionário com dez questões objetivas e descritivas, com o objetivo de obter informações referentes ao cotidiano do professor no ambiente escolar, os obstáculos e desafios encontrados na profissão, a relação professor-aluno, entre outros aspectos.

Os encontros com os professores para a coleta das informações foram realizados nos intervalos entre as aulas ou no horário do recreio/intervalo das aulas. O questionário proposto aos professores participantes da pesquisa se encontra no Quadro 1, a seguir: 
Quadro 1: Questões respondidas pelos participantes da pesquisa

\section{QUESTÕES}

1) Sexo: ( ) feminino ( ) masculino

2) $\mathrm{O}(\mathrm{s})$ colégio(s) em que você trabalha estão localizados em que região do município de Tibagi-PR na:

( ) Zona Urbana ( ) Zona Rural ( ) Trabalho em colégios da Zona Urbana e da Zona Rural

3) Você se sente realizando profissionalmente?

( ) Sinto-me pouco realizado profissionalmente.

( ) Sinto-me realizado profissionalmente.

( ) Não estou realizado profissionalmente.

( ) Outro:

4) Qual a sua carga horária semanal de trabalho?

( ) Entre 8 e 16 horas semanais

( ) Até 20 horas semanais

( ) Entre 20 e 30 horas semanais

( ) 40 horas semanais.

( ) Mais que 40 horas semanais

5) Há quantos anos você já trabalha como professor (a)?

6) Em quantos colégios trabalha?

7) Quais os desafios que você identifica no cotidiano do trabalho?

8) Como é a sua relação com os alunos? E com os demais professores e funcionários?

9) Como seria o aluno ideal para você?

10) Você gosta da sua profissão? Explique.

Fonte: elaboração dos pesquisadores (2017).

As respostas às questões referentes ao Tempo de Serviço, à Carga Horária Semanal e ao Número de Colégios em que os professores atuam foram sistematizadas na Tabela 2, a seguir:

Tabela 2: Relação entre Tempo de Serviço, Carga Horária Semanal e Número de Instituições Escolares (IE) dos participantes da pesquisa - jul./set. $2017\left(^{*}\right)$

\begin{tabular}{c|c|c|c|c|c|c|c|c}
\hline \multirow{2}{*}{$\begin{array}{c}\text { Sujeitos de } \\
\text { Pesquisa }\end{array}$} & \multicolumn{3}{|c|}{ Tempo de Serviço em Anos } & \multicolumn{2}{c|}{$\begin{array}{c}\text { Carga Horária } \\
\text { Semanal }(\mathrm{H} / \mathrm{A})\end{array}$} & \multicolumn{3}{c}{$\begin{array}{c}\text { Número de IE em } \\
\text { que leciona }\end{array}$} \\
\cline { 2 - 9 } & Até 10 & Até 20 & Mais de 20 & $40 \mathrm{~h}$ & $60 \mathrm{~h}$ & 1 & 2 & 3 \\
\hline $100 \%(7)$ & $28 \%(2)$ & $42 \%(3)$ & $28 \%(2)$ & $85 \%(6)$ & $15 \%(1)$ & $28 \%(2)$ & $42 \%(3)$ & $28 \%(2)$ \\
\hline
\end{tabular}

$\left({ }^{*}\right)$ Margem de erro em torno de $2 \%$.

Fonte: dados de pesquisa dos autores (2017). 
Quanto às situações identificadas pelos professores como desafios, as respostas foram organizadas no Gráfico da Figura 3, a seguir:

Figura 3: Desafios encontrados no cotidiano escolar, na percepção dos participantes da pesquisa - jul./set. $2017\left(^{*}\right)$

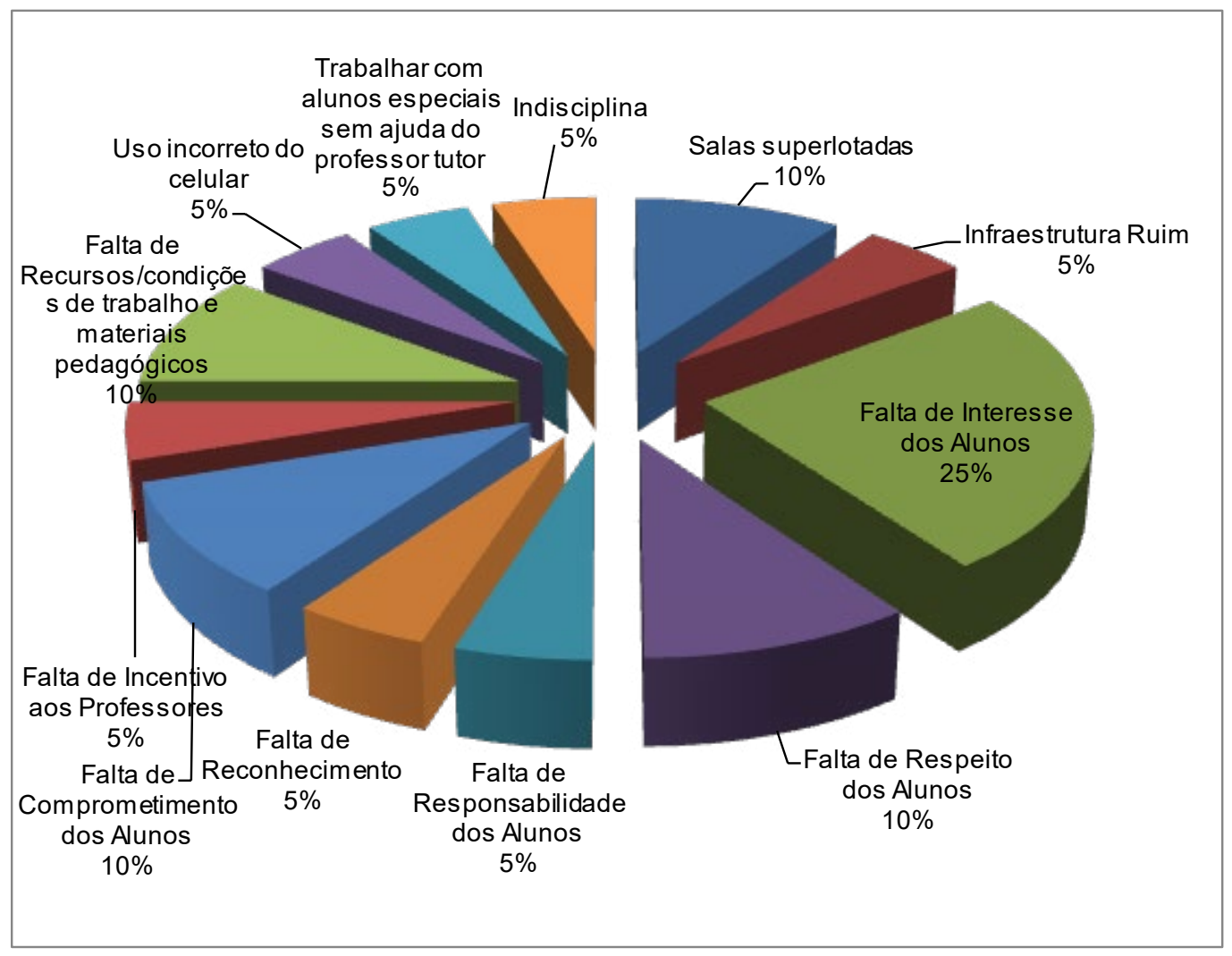

$\left(^{*}\right)$ Margem de erro em torno de $2 \%$.

Fonte: dados de pesquisa dos autores (2017).

Na percepção dos professores, o desafio mais encontrado é a falta de interesse dos alunos, sendo citado por 5 dos 7 participantes; também aparece a falta de responsabilidade, de comprometimento e de respeito dos alunos. As salas superlotadas e a falta de recursos emergem apenas com $10 \%$ de frequência. O difícil acesso às escolas da zona rural - para os professores que enfrentam grandes distâncias e estradas precárias, tendo que utilizar seus próprios recursos para se deslocar - não foi mencionado pelos professores. Assim, apenas desafios encontrados com relação 
aos alunos são os mais citados pelos participantes. E mesmo com o fato dos colégios localizados na zona rural não possuírem sinal telefônico para ligação e para internet, o uso incorreto do celular é citado pelos professores, pois os alunos possivelmente utilizam outros aplicativos disponíveis nestes objetos tecnológicos.

Atrelado a isso, com relação à pergunta de como seria o aluno ideal para eles, a maioria respondeu que seria interessado, educado e responsável. Um aluno que questiona, que participa das aulas e que busca a solução para suas dúvidas, trazendo-as para a sala e partilhando com os demais.

Constata-se a culpabilização apenas dos alunos como desinteressados pelas aulas em detrimento de uma visão ampla de todas as condições estruturais que estão colocadas ao trabalho docente. Esses elementos também estão colocados em outras pesquisas, como a de Rodrigues, Aragão e Rodrigues (2016) que fazem alusão à:

[...] culpabilização da criança que fracassa na escola, a partir da unilateralidade do olhar, quando a escola se recusa a discutir seus critérios de avaliação, seleção e classificação, [e desconsidera] os contextos sociais, familiares e econômicos dos alunos, [ao] considerar que estes alunos apresentam desempenhos iguais, adquirem as suas competências e habilidades a partir do mesmo método pedagógico e com o mesmo ritmo de aprendizagem.

Atrelado a isso, apresentam-se as perspectivas de realização profissional, pois, por um lado, há a culpabilização dos alunos pelo seu fracasso na escola; por outro, há a culpabilização dos professores por seu trabalho docente exitoso ou não frente aos critérios estabelecidos externamente à escola. Quanto à realização profissional, na pesquisa com os professores, 04 participantes se consideram realizados, 03 pouco realizados e nenhum se sente não realizado.

Apenas 01 dos participantes disse que não gosta da profissão, com a seguinte resposta: "Não, é profundamente frustrante, pois não há reconhecimento pelo trabalho". Outros 02 responderam que gostam apesar dos pontos ruins e da desvalorização, e 04 responderam que gostam, pois consideram gratificante e uma experiência significativa.

A Professora Maria1: "Sim, a disciplina de ciências proporciona-me experiências significativas e amplas. Adoro o contato pessoal com meus alunos, o reconhecimento deve ser deles e a realização nossa. Para o Estado somos invisíveis”. Aspectos este que também são considerados por Zacharias et al. ( 2011) ao afirmar: 
A frustração da imagem idealizada pelo docente durante a formação que não é alcançada no trabalho em prática, a falta de recursos disponibilizados pela escola dificultando assim o trabalho do professor, uma gestão de trabalho mal sucedida, a disparidade entre o que um professor é e como ele realmente queria ser, a desvalorização da docência tanto pelo próprio docente como pela sociedade que acredita não ser um trabalho de grande futuro e sucesso, os salários baixos e a falta de segurança contra a violência nas escolas. Ser professor exige muito mais que uma formação acadêmica, requer inúmeros saberes e desafios, o que leva ao esgotamento, ao cansaço e a perda da autoestima.

Ainda com relação a valorização profissional, o professor João considera que: "Sim, entendo como uma profissão nobre, onde tenho a possibilidade de interagir com meus alunos, mostrando que a educação pode ser o caminho para sua mudança de vida" e a Professora Joana ${ }^{3}$ completa essa asserção ao responder: "Sim, porque não saberia (não me vejo) fazendo outra coisa, pois levei um tempo me preparando para ser professora".

A perspectiva de observação e entendimento dos professores citados acenam para a valorização profissional a partir da compreensão da profissão docente como uma profissão comprometida com a formação humana. As contribuições da Professora Joana, em especial, apontam para o processo de identificação do trabalhador com o seu trabalho; contudo, uma relação atrelada ao processo formativo do próprio docente enquanto trabalhador da educação.

No entanto, a partir dos dados apresentados e discutidos, pode-se caracterizar o trabalho dos professores de Ciências e Biologia de Tibagi centrado na compreensão do trabalho reduzido à prática pedagógica na sala de aula e na culpabilização dos alunos pelo desinteresse nas aulas.

Em face disso, há algumas constatações como: a naturalização das condições objetivas e de infraestrutura de trabalho e do trabalho precarizado dos professores, de tal forma que não se questionam as dificuldades de acesso às escolas, as dificuldades estruturais dos espaços nos quais as aulas acontecem. Ou seja, eles não consideram esses elementos como problemas que afetem a sua prática pedagógica, como também não emerge a necessidade de problematizar a democratização do acesso à educação nas cidades interioranas. 


\section{Considerações finais}

A pesquisa descrita neste artigo, a qual é oriunda de um Trabalho de Conclusão

de Curso, objetivou analisar as características e perspectivas dos docentes sobre o trabalho dos professores de Ciências e Biologia de Tibagi-PR, nas especificidades e na singularidade desta cidade paranaense.

Ressalta-se a importância da discussão acerca do trabalho dos professores, em especial no contexto desta pesquisa nesse município, e atenta-se para as seguintes constatações:

(1) a necessidade da democratização da Educação e do acesso à Educação;

(2) a naturalização das condições objetivas e estruturais do trabalho precarizado dos professores em questão;

(3) a garantia de políticas de valorização e manutenção dos professores nas cidades interioranas e nas zonas rurais, pois a maioria dos professores estão para aposentar-se e há poucos professores jovens atuando nos Colégios da região em estudo;

(4) a culpabilização apenas dos alunos como desinteressados pelas aulas em detrimento de uma visão mais ampla de todas as condições estruturais que permeiam os processos educativos no Ensino de Ciências e Biologia.

Entende-se que o objetivo traçado para esta pesquisa foi alcançado, mas, tendo em vista a complexidade teórica necessária para a discussão dos dados encontrados, optou-se por apresentar as primeiras análises referentes à pesquisa, com o intuito de dar continuidade às investigações e às discussões em artigos futuros. 


\section{The Work of Science and Biology Teachers in the State High Schools of Tibagi-PR: precariousness and naturalization}

\section{Abstract}

Studying the conditions of teacher work is fundamental for a critical reflection on the pedagogical praxis as it relates to science and biology education. Starting from this notion, this research aimed to analyze teachers' perspectives and characteristics within their work in science and biology in the schools of Tibagi-PR, with special attention to the specifics and singularity of this large town. In order to do so, we carried out both theoretical and empirical studies with seven teachers who operate in the four state high schools located in the urban and rural areas of the community. The data has gone through quantitative analysis, which has wielded the following results: 1) there is a need for democratization of education and the access to it; 2) there is a naturalization of the precariousness of the objective and structural conditions of the work of the teachers in question; 3 ) the guarantee of policies of valorization and support of teachers in countryside towns and rural areas is a must, seeing as many teachers are close to retirement age and there are few new teachers operating in the high schools studied; 4) students receive all the blame for their lack of interest in the classes, instead of being considered within a wider view of the structural conditions which permeate education processes within science and biology teaching. This essay presents the preliminary analyses we have reached, with the assumption that our study will continue.

Keywords: Science education. Biology education. Biology teachers. Work.

\section{Notas}

1 Nomes fictícios.

2 Nomes fictícios.

3 Nomes fictícios.

\section{Referências}

BARROS, José Deomar de Souza; SILVA, Maria de Fátima Pereira da; VÁSQUEZ, Silvestre Fernández. A prática docente mediada pelo estágio supervisionado. Atos de pesquisa em educação - PPGE/ME FURB, v. 6, n. 2, p. 510-520, maio/ago. 2011. Disponível em: https://proxy.furb. br/ojs/index.php/atosdepesquisa/article/view/1661 Acesso em: 26 dez. 2019.

BENEVIDES-PEREIRA, Ana Maria Teresa. Considerações sobre a síndrome de Burnot e seu impacto no ensino. Boletim de Psicologia, 2012, Vol. LXII, n. 137, p. 155-168. Disponível em: http://pepsic.bvsalud.org/scielo.php?script=sci_arttext\&pid=S0006-59432012000200005. Acesso em: 26 dez. 2019.

BRASIL.MEC. Educação do Campo: diferenças mudando paradigmas. Cadernos de subsídios. SECAD 2. Secretaria de Educação Continuada, Alfabetização e Diversidade. INEP/MEC. BRASÍLIA - DF, 2007. 
CRUZ, Moraes; LEMOS, Jadir Camargo; WELTER, Marisete M.; GUISSO, Luciane. Saúde docente, condições e carga de trabalho. Revista Electrónica de Investigación y Docencia (REID), 4, p. 147-160, Julio 2010. Disponível em: https://revistaselectronicas.ujaen.es/index.php/ reid/article/download/1024/863/ Acesso em: 26 dez. 2019.

DELIZOICOV, Demétrio; ANGOTTI, José Peres; PERNAMBUCO, Marta Maria. Ensino de ciências, fundamentos e métodos. 4. ed. São Paulo: Cortez, 2011.

ENGUITA, Mariano Fernández. A face oculta da escola. Editora Artes Médicas. Porto Alegre, 1989.

FLICK, Uwe. Introdução à pesquisa qualitativa. $3^{\text {a }}$ edição. Porto Alegre: Artmed, 2009.

GASPARINI, Sandra Maria; BARRETO, Sandhi Maria; ASSUNÇÃO, Ada Ávila. O professor, as condições de trabalho e os efeitos sobre sua saúde. Educação e Pesquisa, São Paulo, v. 31, n. 2, p. 189-199, maio/ago. 2005. Disponível em: http://www.scielo.br/pdf/ep/v31n2/a03v31n2.pdf. Acesso em: $26 \mathrm{dez} .2019$.

GOOGLE MAPS. Mapa de Tibagi, Paraná, Brasil. Disponível em: https://www.google.com.br/ maps/place/Tibagi+-+PR,+84300-000/@-24.6838106. Acesso em: 5 maio 2019.

GROCHOSKA, Marcia Andreia. Políticas educacionais e a valorização do professor: carreira e qualidade de vida dos professores de educação básica do município de São José dos Pinhais/ PR. Tese (Doutorado em Educação) - Programa de Pós-Graduação em Educação, Universidade Federal do Paraná, Curitiba, 2015.

LUKÁCS, György. Ontologia do ser social: os princípios ontológicos fundamentais de Marx. São Paulo: LECH, 1979.

LUKÁCS, György. Para uma ontologia do ser social I. Trad. Carlos Nelson Coutinho, Mario Duayer, Nélio Schneider. 1ª edição. São Paulo: Boitempo, 2012.

LUKÁCS, György. Para uma ontologia do ser social II. Trad. Nélio Schneider, Ivo Tonet, Ronaldo Vielmi Fortes. 1ª edição. São Paulo: Boitempo, 2013.

MARX, Karl. O capital. 7. ed. São Paulo: Difel. 2002.

MARX, Karl. O capital: livro 1. V. 1. Rio de Janeiro: Civilização Brasileira, 1974.

MASSON, Gisele. A valorização dos professores e a educação básica nos estados. Revista Retratos da Escola, Brasília, v. 10, n. 18, p. 157-174, jan./jun. 2016. Disponível em: http://retratosdaescola. emnuvens.com.br/rde/article/viewFile/656/693. Acesso em: 26 dez. 2019.

MORETTI, J. S. S.; MASSON, Gisele. A valorização dos professores em municípios do Paraná: análise dos planos de carreira. Jornal de Políticas Educacionais, v. 9, n. 17-18, p. 111-124, Jan.-Jun. e Ago.-Dez. 2015. Disponível em: https://revistas.ufpr.br/jpe/article/view/44106. Acesso em: 26 dez. 2019.

NEVES, Mary Yale Rodrigues; SILVA, Edith Seligmann. A dor e a delícia de ser (estar) professora: trabalho docente e saúde mental. Estudos e Pesquisas em Psicologia, UERJ, Rio de Janeiro, ano 6, n. 1, p. 63-75, 2006. Disponível em: http://pepsic.bvsalud.org/pdf/epp/v6n1/v6n1a06.pdf. Acesso em: 8 jan. 2019. 
RODRIGUES, Janine Marta Coelho; ARAGÃO, Wilson Honorato; RODRIGUES, Silvestre Coelho. Políticas públicas de educação no brasil: fracasso escolar, culpabilização dos alunos e inocentização da escola. RPGE- Revista on-line de Política e Gestão Educacional, Araraquara, v. 21, n. esp. 2, p. 979-1015, nov. 2016. Disponível em: https://periodicos.fclar.unesp.br/rpge/article/ view/10372/6959. Acesso em: 4 mar. 2020.

SANTOS, Bettina Steren dos; ANTUNES, Denise Dalpiaz; BERNARDI, Jussara. O docente e sua subjetividade nos processos motivacionais. Educação, Porto Alegre, v. 31, n. 1, p. 46-53, jan./ abr. 2008. Disponível em: http://revistaseletronicas.pucrs.br/ojs/index.php/faced/article/view/2757. Acesso em: 26 dez. 2019.

SILVA, Guilherme Leonardo Freitas Silva; ROSSO, Ademir José. As condições do trabalho docente dos professores das escolas públicas de Ponta Grossa - PR. In: CONGRESSO NACIONAL DE EDUCAÇÃO. EDUCERE, 8., 2008, Curitiba. Atas... Formação de professores, 2008, v. 1, p. 2040-2051. Disponível em: https://educere.bruc.com.br/arquivo/pdf2008/495_536.pdf. Acesso em: 26 dez. 2019.

SOUZA, Rodrigo Diego de. Trabalho e formação de professores de biologia no Estado do Paraná, Brasil. Tese (Doutorado em Educação Científica e Tecnológica) - Programa de Pós-Graduação em Educação Científica e Tecnológica, Universidade Federal de Santa Catarina, Florianópolis, 2019.

ZACHARIAS, Jamile; MENDES, Aline Rocha; LETTNIN, Carla; DOHMS, Karina Pacheco; MOSQUERA, Juan José Mouriño; STOBÄUS, Claus Dieter. Saúde e Educação: do mal-estar ao bem-estar docente. Revista Educação por Escrito - PUCRS, v. 2, n.1, jun. 2011. Disponível em: http://revistaseletronicas.pucrs.br/ojs/index.php/porescrito/article/download/8674/6642. Acesso em: $26 \mathrm{dez} .2019$. 